\title{
Efeito do Óleo de Linhaça e do Óleo de Amendoim sobre a Vulcanização da Borracha Natural (NR). Parte I: Modelo Generalizado
}

\author{
Alexandre Bezerra, Alex. C. S. Santos, Helson M. da Costa \\ Departamento de Materiais (DEMAT), Instituto Politécnico (IPRJ), \\ Universidade do Estado do Rio de Janeiro (UERJ) \\ Valéria D. Ramos, Helson M. da Costa \\ Universidade Estácio de Sá (UNESA)
}

\begin{abstract}
Resumo: O efeito de dois óleos vegetais, óleo de linhaça e óleo de amendoim, em composições de borracha natural (NR) foi avaliado. Um sistema de vulcanização convencional foi escolhido e, após a mistura os parâmetros reométricos $\left(\mathrm{M}_{\ell}, \mathrm{M}_{\mathrm{h}}, \mathrm{t}_{\mathrm{s} 1} \mathrm{e} \mathrm{t}_{90}\right)$ foram analisados. A cinética de vulcanização também foi estudada através de um modelo simplificado. A constante de taxa $(k)$ foi determinada em $160^{\circ} \mathrm{C}, 170^{\circ} \mathrm{C}$ e $180^{\circ} \mathrm{C}$ e a energia de ativação ( $\mathrm{E}_{\mathrm{a}}$ ) global do processo foi estimada. Os resultados experimentais permitem concluir que os óleos sozinhos ou combinados são capazes de atuar como ativadores e, juntamente com os demais ingredientes da composição, de vulcanizar a borracha. No entanto, uma densidade de ligações cruzadas satisfatória só é atingida quando o ácido esteárico está presente.
\end{abstract}

Palavras-chaves: Borracha natural, vulcanização, óleos vegetais.

\section{Effect of Linseed Oil and Peanut Oil upon Natural Rubber (NR) Vulcanization. Part I: General Model}

Abstract: The effect of two vegetable oils, linseed oil and peanut oil, in natural rubber (NR) compositions was available. A conventional system of vulcanization was chosen and, after the mixtures the rheometer parameters $\left(\mathrm{M}_{\ell}, \mathrm{M}_{\mathrm{h}}, \mathrm{t}_{\mathrm{s} 1}\right.$ e $\left.\mathrm{t}_{90}\right)$ were analyzed. The vulcanization kinetics was also studied through the simplified model. The constant rate $(k)$ was determined at $160{ }^{\circ} \mathrm{C}, 170{ }^{\circ} \mathrm{C}$ and $180^{\circ} \mathrm{C}$, and the global activation energy $\left(\mathrm{E}_{\mathrm{a}}\right)$ of the process was estimated. Experimental results show that oils alone or combined are capable of acting as activators and, together with the other components, vulcanize rubber. However, an adequate crosslinking density is only reached when stearic acid is present.

Keywords: Natural rubber, vulcanization, vegetable oils.

\section{Introdução}

Na indústria da borracha, a preparação de um produto comercial específico requer a seleção de matériasprimas básicas para a obtenção de uma formulação. Em composições elastoméricas usuais, entre os diversos ingredientes, os chamados ativadores são usados. Esses ingredientes formam complexos químicos com os aceleradores e, então, auxiliam na obtenção de maiores taxas de vulcanização e aumento das propriedades finais do vulcanizado ${ }^{[1,2]}$.

Geralmente, os ativadores são compostos inorgânicos (óxido de zinco, óxido de magnésio, entre outros) que atuam em conjunto com compostos orgânicos (aminas, sais de aminas com ácidos fracos, ácidos graxos, entre outros). As quantidades e os tipos em particular de ativadores dependem das quantidades dos outros ingredientes presentes bem como do tipo de acelerador usado ${ }^{[1,2]}$.

Em busca de fontes naturais, renováveis e de baixo custo para a obtenção de matérias-primas, a indústria química, há algum tempo, tem se utilizado dos óleos vegetais e seus derivados. Os principais constituintes dos óleos vegetais são os triacilgliceróis ou triglicerídeos. Os triacilgliceróis podem ser simples, nos quais todos os três grupos acila são os mesmos; ou, mais comumente, mistos onde os grupos acila são diferentes. A hidrólise de uma gordura (triacilgliceróis sólidos à temperatura ambiente) ou óleo (triacilgliceróis líquidos à temperatura ambiente) produz uma mistura de ácidos graxos. Os ácidos graxos contabilizam $95 \%$ da massa total dos triacilgliceróis e seu conteúdo é característico de cada óleo ${ }^{[3-5]}$.

Em função da presença de ácidos graxos na composição química, o efeito de óleos vegetais em formulações de borracha é alvo de atenção. Exemplos podem ser encontrados, por exemplo, nas investigações de Ismail et al. ${ }^{[6,7]}$, os quais analisaram a ação do óleo de palma em composições de borracha natural (NR) e borracha natural epoxidada (ENR) contendo carga ou não. Em outro estudo, da Costa et al. ${ }^{[8]}$ avaliaram o potencial do óleo de mamona como um ativador para a vulcanização de composições de NR contendo sílica. Em nenhuma das investigações, no entanto, uma análise aprofundada do efeito dos óleos vegetais no mecanismo da vulcanização foi considerado. 
Na presente estudo, a influência de dois óleos vegetais comestíveis e facilmente encontrados no comércio - o óleo de amendoim e o óleo de linhaça - em composições de borracha natural foi considerado. Utilizando-se um sistema de vulcanização convencional, a cinética de vulcanização foi acompanhada através de um modelo generalizado e o potencial de substituição do ácido esteárico (ingrediente costumeiro em composições de NR) pelos óleos foi estimado.

\section{Experimental}

Todos os materiais foram usados como recebidos. Borracha natural foi fornecida pela Michelin Brasil. O antioxidante usado, Irganox 1010, e o óxido de zinco foram doados pela Uniroyal Química S.A. O acelerador $\mathrm{N}$ - $t$-butil-2-benzotiazol-sulfenamida (TBBS) foi doado pela Bann Química Ltda. Os outros ingredientes da composição, ácido esteárico e enxofre, foram reagentes adquiridos junto à Vetec Química Fina Ltda.

Os óleos de amendoim e de linhaça comestíveis foram obtidos no comércio local e são manufaturados pela Indústria de Óleos Vegetais Pazze Ltda. As características físico-químicas dos óleos encontram-se na Tabela 1. A formulação usada está na Tabela 2, a qual foi utilizada no preparo das sete composições de borracha natural contendo diferentes razões de ácido esteárico / óleo de amendoim / óleo de linhaça.

As misturas foram conduzidas em linhas gerais de acordo com a norma ASTM D3182. Um misturador de rolos Berstoff, modelo 90-3Wo/1335/69, foi utilizado com uma razão de fricção de 1:1,25. Após a plastificação da borracha, o óxido de zinco foi adicionado e, após a incorporação, os demais ingredientes foram adicionados em conjunto. Para a obtenção das curvas de torque elástico (S') versus o tempo, as diferentes composições foram

Tabela 1. Características físico-químicas dos óleos vegetais ${ }^{[9]}$.

\begin{tabular}{|c|c|}
\hline Óleo de amendoim & Valor de referência \\
\hline Peso Específico $\left(25^{\circ} \mathrm{C}\right)$ & $0,911-0,914 \mathrm{~g} / \mathrm{cm}^{3}$ \\
\hline Índice de Refração $\left(25^{\circ} \mathrm{C}\right)$ & $1,460-1,465$ \\
\hline Índice de Iodo & $80-106 \mathrm{~g} \mathrm{I}_{2} / 100 \mathrm{~g}$ \\
\hline Índice de Saponificação & $187-196 \mathrm{mg} \mathrm{KOH} / \mathrm{g}$ \\
\hline Matéria Insaponificável & $<1,0 \%$ \\
\hline Acidez, óleo refinado & $<0,3 \mathrm{~g}$ de ácido oléico / $100 \mathrm{~g}$ \\
\hline Índice de Peróxido & $<10,0 \mathrm{meq} / \mathrm{kg}$ \\
\hline Ácidos graxos & Composição (\%) \\
\hline Ácido Mirístico (C14:0) & $<0,6$ \\
\hline Ácido Palmítico (C16:0) & $6,0-16,0$ \\
\hline Ácido Palmitoléico (C16:1) & $<1,0$ \\
\hline Ácido Margárico $(C 17: 0)$ & $<0,1$ \\
\hline Heptadecenóico (C17:1) & $<0,1$ \\
\hline Ácido Esteárico (C18:0) & $1,3-6,5$ \\
\hline Ácido Oléico (Ômega 9) (C18:1) & $35,0-72,0$ \\
\hline Ácido Linoléico (Ômega 6) (C18:2) & $13,0-45,0$ \\
\hline Ácido Linolênico (Ômega 3) (C18:3) & $<0,3$ \\
\hline Ácido Araquídico (C20:0) & $1,0-3,0$ \\
\hline Ácido Eicosenóico (C20:1) & $0,5-2,1$ \\
\hline Ácido Behênico (C22:0) & $1,0-5,0$ \\
\hline Ácido Erúcico (C22:1) & $<0,3$ \\
\hline Ácido Lignocérico (C24:0) & $0,5-3,0$ \\
\hline Óleo de linhaça & Valor de referência \\
\hline Peso Específico $\left(25^{\circ} \mathrm{C}\right)$ & $0,924-0,930 \mathrm{~g} / \mathrm{cm}^{3}$ \\
\hline Índice de Refração $\left(25^{\circ} \mathrm{C}\right)$ & $1,477-1,482$ \\
\hline Índice de Iodo & $170-203 \mathrm{~g} \mathrm{I}_{2} / 100 \mathrm{~g}$ \\
\hline Índice de Saponificação & $188-196 \mathrm{mg} \mathrm{KOH} / \mathrm{g}$ \\
\hline Matéria Insaponificável & $0,1-2 \%$ \\
\hline Acidez, óleo refinado & $<0,15 \mathrm{~g}$ de ácido oléico / $100 \mathrm{~g}$ \\
\hline Ácidos graxos & Composição (\%) \\
\hline Ácido Palmítico (C16:0) & $5,7-7,0$ \\
\hline Ácido Esteárico (C18:0) & $3,0-4,0$ \\
\hline Ácido Oléico (Ômega 9) (C18:1) & $20,0-20,3$ \\
\hline Ácido Linoléico (Ômega 6) (C18:2) & $17,0-17,3$ \\
\hline Ácido Linolênico (Ômega 3) (C18:3) & $52,0-54,0$ \\
\hline Ácido Araquídico (C20:0) & $<0,1$ \\
\hline
\end{tabular}


vulcanizadas no curômetro Rheoline Oscillating Disc Rheometer (Prescott Instruments Ltd.) com amplitude de oscilação de $\pm 1^{\circ}$. Três temperaturas $\left(160,170\right.$ e $\left.180^{\circ} \mathrm{C}\right)$ foram selecionadas para o cálculo dos parâmetros cinéticos - constante de taxa para a reação $(k)$ e energia de ativação $\left(\mathrm{E}_{\mathrm{a}}\right)$. Em cada temperatura, duas amostras de cada mistura foram analisadas.

\section{Resultados e Discussão}

\section{Dados reométricos}

Na Tabela 3, os dados reométricos, obtidos nas temperaturas de $160-180{ }^{\circ} \mathrm{C}$, das composições de borracha natural contendo as diferentes proporções de ácido esteárico / óleo de amendoim / óleo de linhaça são apresentados.

Após a câmara interna do reômetro de disco oscilatório ser selada, a amostra de borracha, sob o efeito da temperatura e pressão, flui continuamente até envolver o disco oscilatório e atinge-se um registro de torque

Tabela 2. Composição das diferentes misturas de borracha natural contendo os óleos vegetais.

\begin{tabular}{lcc}
\hline \multicolumn{1}{c}{ Material } & \multicolumn{2}{c}{ Concentração (phr) } \\
\hline Borracha natural (NR) & \multicolumn{2}{c}{100} \\
ZnO & \multicolumn{2}{c}{4,0} \\
TBBS $^{a}$ & \multicolumn{2}{c}{1,0} \\
Irganox 1010 & \multicolumn{2}{c}{1,2} \\
Enxofre & \multicolumn{2}{c}{2,8} \\
& $\mathrm{NR}_{1}$ & $3,0 / 0,0 / 0,0$ \\
& $\mathrm{NR}_{2}$ & $0,0 / 3,0 / 0,0$ \\
& $\mathrm{NR}_{3}$ & $0,0 / 0,0 / 3,0$ \\
Ác.Est. / Ol. Linh. / Ol. Amend. & $\mathrm{NR}_{4}$ & $1,5 / 1,5 / 0,0$ \\
& $\mathrm{NR}_{5}$ & $1,5 / 0,0 / 1,5$ \\
& $\mathrm{NR}_{6}$ & $0,0 / 1,5 / 1,5$ \\
& $\mathrm{NR}_{7}$ & $1,0 / 1,0 / 1,0$ \\
\hline
\end{tabular}

${ }^{a} \mathrm{~N}$ - $\mathrm{t}$-butil-2-benzotiazol-sulfenamida; ${ }^{\mathrm{b} A n t i o x i d a n t e}$ fenólico (3-(3,5-di-t-butil-4-hidróxifenil)propionato). mínimo $\left(\mathbf{M}_{\ell}\right)$. Tal valor está diretamente relacionado à processabilidade das composições não vulcanizadas. Quanto maior o valor registrado de $\mathrm{M}_{\ell}$, mais difícil é o processamento da composição em questão, ou seja, mais viscosa é a mistura elastomérica ${ }^{[2,10]}$.

De maneira geral, pode ser observado que, em todas as composições de NR, a temperatura de vulcanização pouco influenciou nos resultados experimentais, ou seja, praticamente não houve variação do torque mínimo quando se considera uma mesma composição. Entre as misturas contendo apenas um único ingrediente como ativador (NR1, NR2 e NR3), a mistura NR3 contendo óleo de amendoim apresentou, em média, valores de $\mathrm{M}_{\imath}$ duas vezes maiores quando comparados aos obtidos pela mistura NR1, a qual contém apenas ácido esteárico.

Para as misturas contendo dois ou três ingredientes como ativador (NR4 a NR7), a mistura NR6 (óleo de amendoim e óleo de linhaça 50\%-50\%) apresentou os maiores valores de $\mathbf{M}_{\ell}$ - entre 9 e $10 \mathrm{dN}$.m.

Indiretamente, em composições que não contêm cargas, $M_{\ell}$ também pode fornecer valiosas informações sobre a velocidade da reação de vulcanização. Os valores elevados de $M_{\ell}$ significam que as reações entre os ingredientes da composição tiveram início em menor tempo. Desta forma, a viscosidade da mistura não pode ser reduzida o suficiente para que um registro baixo de $\mathrm{M}_{\ell}$ venha a ser obtido. Tal afirmação é corroborada quando os valores do tempo de pré-cura $\left(\mathrm{t}_{\mathrm{sl}}\right)$ são analisados na Tabela 3.

$\mathrm{O}$ tempo de pré-cura $\left(\mathrm{t}_{\mathrm{s} 1}\right)$ refere-se à vulcanização prematura, isto é, a reticulação da composição durante o estágio de processamento. Isto reduz as propriedades plásticas da composição interferindo na operação de moldagem do produto final. O tempo de pré-cura, então, geralmente define o tempo disponível para o processamento antes do início da vulcanização, em uma temperatura particular ${ }^{[2]}$. Através da Tabela 3, observa-se que um aumento na temperatura de vulcanização reduz os tempos de pré-cura para todas as composições de $\mathrm{NR}^{[11]}$.

Tabela 3. Dados reométricos obtidos para as diferentes composições de borracha natural (NR).

\begin{tabular}{|c|c|c|c|c|c|c|c|c|c|c|c|c|}
\hline \multirow{2}{*}{ Composição } & \multicolumn{4}{|c|}{$160^{\circ} \mathrm{C}$} & \multicolumn{4}{|c|}{$170^{\circ} \mathrm{C}$} & \multicolumn{4}{|c|}{$180^{\circ} \mathrm{C}$} \\
\hline & ${ }^{\mathrm{a}} \mathbf{M}_{\ell}$ & ${ }^{\mathrm{a}} \mathbf{M}_{\mathrm{h}}$ & ${ }^{b} t_{s 1}$ & ${ }^{b} t_{90}$ & ${ }^{\mathrm{a}} \mathbf{M}_{\ell}$ & ${ }^{\mathrm{a}} \mathbf{M}_{\mathrm{h}}$ & ${ }^{b} t_{\mathrm{s} 1}$ & ${ }^{b} \mathbf{t}_{90}$ & ${ }^{\mathrm{a}} \mathbf{M}_{\ell}$ & ${ }^{\mathrm{a}} \mathbf{M}_{\mathrm{h}}$ & $\mathrm{b}_{\mathrm{s} 1}$ & ${ }^{b} t_{90}$ \\
\hline \multirow{2}{*}{ NR1 } & 3,28 & 65,07 & 3,95 & 9,25 & 3,24 & 62,37 & 2,25 & 4,85 & 3,20 & 60,14 & 1,68 & 3,75 \\
\hline & 3,22 & 65,33 & 3,85 & 9,10 & 3,10 & 61,91 & 2,09 & 4,80 & 3,21 & 60,48 & 1,81 & 3,81 \\
\hline \multirow{2}{*}{ NR2 } & 5,01 & 56,16 & 3,12 & 6,43 & 4,96 & 52,35 & 2,00 & 4,46 & 5,20 & 49,78 & 1,48 & 2,94 \\
\hline & 5,03 & 55,54 & 3,16 & 6,45 & 5,19 & 52,75 & 1,72 & 4,14 & 5,14 & 50,17 & 1,43 & 2,99 \\
\hline \multirow{2}{*}{ NR3 } & 6,67 & 57,71 & 3,00 & 6,70 & 6,71 & 54,13 & 2,25 & 4,98 & 7,06 & 52,30 & 1,58 & 3,20 \\
\hline & 6,75 & 57,87 & 2,98 & 6,81 & 6,82 & 53,98 & 2,24 & 5,35 & 6,43 & 51,84 & 1,23 & 2,81 \\
\hline \multirow{2}{*}{ NR4 } & 3,90 & 64,39 & 3,87 & 8,40 & 3,94 & 61,12 & 2,35 & 4,98 & 4,02 & 59,94 & 1,62 & 3,38 \\
\hline & 4,05 & 64,59 & 3,91 & 8,39 & 3,97 & 60,81 & 2,52 & 5,26 & 4,08 & 59,85 & 1,68 & 3,40 \\
\hline \multirow{2}{*}{ NR5 } & 5,75 & 64,52 & 3,74 & 8,23 & 5,71 & 61,53 & 1,95 & 4,36 & 5,84 & 57,91 & 1,48 & 3,49 \\
\hline & 5,76 & 64,21 & 3,96 & 8,89 & 5,87 & 61,36 & 1,84 & 4,01 & 5,93 & 58,76 & 1,55 & 3,53 \\
\hline \multirow{2}{*}{ NR6 } & 9,30 & 58,44 & 2,55 & 6,05 & 9,94 & 56,37 & 2,04 & 4,24 & 9,83 & 53,04 & 1,18 & 2,87 \\
\hline & 9,45 & 58,13 & 2,60 & 6,14 & 9,83 & 55,89 & 2,02 & 4,30 & 9,68 & 51,94 & 1,15 & 2,82 \\
\hline \multirow{2}{*}{ NR7 } & 6,76 & 64,36 & 3,32 & 7,58 & 6,97 & 62,58 & 2,53 & 5,74 & 7,43 & 58,98 & 1,70 & 3,52 \\
\hline & 6,73 & 64,63 & 3,39 & 7,46 & 6,95 & 61,56 & 2,42 & 5,60 & 7,10 & 58,17 & 1,51 & 3,36 \\
\hline
\end{tabular}

${ }^{\text {aUnidade: }} \mathrm{dN} . \mathrm{m}$; ${ }^{\mathrm{b}}$ Unidade: min. 
De um modo geral, quase todas as reações químicas ocorrem mais rápido em temperaturas mais elevadas do que em temperaturas mais baixas ${ }^{[12]}$. Assim, a redução nos valores de $t_{\mathrm{s} 1}$ reflete tal premissa e $t_{\mathrm{s} 1}$ torna-se, em média, duas vezes mais rápido para um aumento de $10{ }^{\circ} \mathrm{C}$ na temperatura. Além disso, conforme comentado na análise de $\mathrm{M}_{\ell}$, as misturas NR3 e NR6 são aquelas que apresentam os menores tempos de pré-cura e, portanto, são as misturas em que formação da rede de ligações cruzadas inicia-se mais prematuramente.

O tempo ótimo de cura $\left(\mathrm{t}_{90}\right)$ é o tempo necessário durante a vulcanização para que uma dada quantidade de ligações cruzadas seja formada, conduzindo a um nível desejado de propriedades ${ }^{[2]}$. $\mathrm{O}$ efeito do aumento da temperatura de vulcanização sobre os valores de $t_{90}$ é novamente visto, e segue o padrão já comentado.

Pela Tabela 3 observa-se que a composição onde o óleo de linhaça (NR2) ou o óleo de amendoim (NR3) são empregados sozinhos, e a composição onde os dois óleos estão presentes (NR6), são aquelas onde a vulcanização ocorre de forma mais rápida; em média, um minuto mais rápida do que a vulcanização da composição padrão NR1 (ácido esteárico como ativador).

O torque máximo $\left(\mathrm{M}_{\mathrm{h}}\right)$ proporciona uma idéia da densidade de ligações cruzadas ou, indiretamente, se o estado de cura está sendo reduzido substancialmente ou não pela presença dos óleos vegetais em substituição total ou parcial ao ácido esteárico.

Pode ser verificado pela Tabela 3 que os valores de $\mathrm{M}_{\mathrm{h}}$ são reduzidos à medida que a temperatura de vulcanização aumenta. Tal redução é explicada pela produção de redes de ligações cruzadas com menor densidade de ligações polissulfídicas, além da formação de grupos sulfídicos intramoleculares e aumento na concentração de sulfeto de zinco $^{[11]}$.

Também é observado na Tabela 3 que as todas as composições de NR apresentam a capacidade de vulcanizar. Contudo, as composições NR2, NR3 e NR6 não apresentam uma reticulação tão efetiva quanto à composição padrão NR1. A presença individual dos óleos ou a simples combinação de ambos embora permita a vulcanização, não é capaz de gerar uma rede de ligações cruzadas em igual magnitude àquela da composição onde apenas o ácido esteárico está presente.

Por outro lado, nas composições NR4 (óleo de linhaça / ácido esteárico, 50\%-50\%), NR5 (óleo de amendoim / ácido esteárico, 50\%-50\%) e NR7 (óleo de linhaça / óleo de amendoim / ácido esteárico, 33,3\%-33,3\%-33,3\%) é possível encontrar um desempenho próximo ao da composição NR1.

Assim sendo, a Tabela 3 induz a pensar que a chave para a explicação da diferença nas redes de ligações cruzadas formadas reside na composição química dos óleos vegetais e na presença de insaturações nos ácidos graxos oriundos dos mesmos. A fim de se avaliar melhor tal hipótese, o estudo da cinética de vulcanização foi conduzido com um modelo simplificado.

\section{Modelo cinético generalizado}

A rota geral do processo de vulcanização pode ser estudada quanto à cinética utilizando-se um modelo generalizado. Assumindo que os valores de torque estão diretamente relacionados à densidade de ligações cruzadas e que a cinética é de primeira ordem, uma expressão pode ser escrita em termos de torque ${ }^{[13,14]}$ :

$$
\ln \left(\frac{M_{h}-M_{\ell}}{M_{h}-M_{t}}\right)=k t
$$

onde $M_{t}$ é o torque registrado em um tempo $t ; M_{\ell}$ e $M_{h}$ representam os torques mínimo e máximo, respectivamente; e $k$ é a constante de taxa da reação de vulcanização. Para que a hipótese de cinética de primeira ordem seja válida, $k$ deve ser estimado nos primeiros estágios da vulcanização, ou seja, onde as reações laterais e/ou competitivas estão ausentes. Assim, os valores de $M_{t}$ foram escolhidos em tempos correspondentes ao intervalo de $25 \%$ a $45 \%$ da variação de torque em relação ao torque mínimo $\left(M_{\ell}\right)$.

A combinação da equação de Arrhenius com Equação 1 gera uma conveniente expressão para o cálculo da energia de ativação aparente para o processo de vulcanização. Utilizando-se dados do reômetro a partir de corridas isotérmicas, a diferentes temperaturas, tem-se ${ }^{[13]}$ :

$$
\frac{E_{a}}{R}=\ln \left(\frac{\ln \left(\frac{\left(t_{45 \%}-t_{25 \%}\right)_{\beta}}{\left(t_{45 \%}-t_{25 \%}\right)_{\alpha}}\right)}{\frac{1}{T_{\beta}}-\frac{1}{T_{\alpha}}}\right)
$$

onde $\left(t_{45 \%}-t_{25 \%}\right)_{\alpha}$ e $\left(t_{45 \%}-t_{25 \%}\right)_{\beta}$ são os incrementos de tempo relacionados às variações no torque de $25 \%$ e $45 \%$, nas temperaturas $T \alpha$ e $T \beta$, respectivamente.

$\mathrm{Na}$ Figura 1 são encontrados os valores das constantes de taxa global de reação $(k)$ para as diferentes composições de NR em função da temperatura. Pode ser observado que:

- De maneira geral, a taxa de reaçãoé, aproximadamente, duplicada ou triplicada para cada aumento de $10{ }^{\circ} \mathrm{C}$

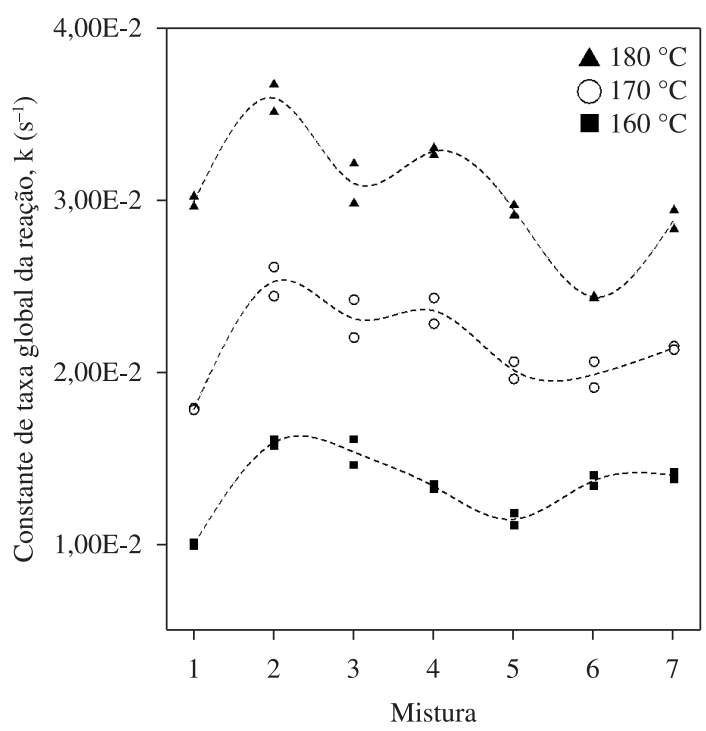

Figura 1. Gráfico do efeito dos óleos vegetais sobre a constante de velocidade global 
na temperatura de vulcanização. Isto é verificado em todas as composições, embora o aumento de fato seja diferente de uma composição para outra;

- Para as composições de NR contendo apenas um ativador (NR1, NR2 e NR3), a composição padrão NR1 com ácido esteárico exibe sempre o menor valor de $k$. Por outro lado, a presença de óleo de linhaça em NR2 conduz aos valores mais altos de $k$ em relação às demais, sobretudo na temperatura de $180^{\circ} \mathrm{C}$; e

- Nas composições com dois ou três ingredientes combinados (NR4 a NR7), diferenças acentuadas surgem à medida que a temperatura de vulcanização passa de $160 \mathrm{C}$ para $180^{\circ} \mathrm{C}$. A composição NR4 (óleo de linhaça / ácido esteárico) passa a exibir o maior de valor de constante de taxa, enquanto a composição NR6 (óleo de linhaça / óleo de amendoim) apresenta comportamento oposto.

Quando se analisa a estrutura dos ácidos graxos envolvidos nesta investigação, a explicação para as diferenças nos valores de $k$ podem ser avaliados. As cadeias de ácidos graxos saturados podem adotar várias conformações que tendem a ser totalmente estendidas, pois isto minimiza as repulsões estéricas entre os grupos metilenos vizinhos. Ácidos graxos saturados organizam-se com facilidade em cristais e como as atrações de van der Waals são fortes, eles possuem pontos de fusão relativamente elevados (ácido esteárico, P.F. $=70{ }^{\circ} \mathrm{C}$ ). Os pontos de fusão aumentam com o aumento da massa molecular. A configuração cis da ligação dupla de um ácido graxo insaturado impõe uma curva rígida à cadeia de carbono que interfere com a organização cristalina, causando uma redução da atração de van der Waals, entre as moléculas. Consequentemente, ácidos graxos insaturados possuem pontos de fusão mais baixos (ácido oléico, P.F. $=4{ }^{\circ} \mathrm{C}$; ácido linolênico, P. F. $\left.=-11^{\circ} \mathrm{C}\right)^{[15]}$.

Durante a etapa de mistura dos ingredientes e processamento no misturador de rolos foi observado que nas composições onde, pelo menos, um dos óleos vegetais estava presente, havia uma solubilização parcial dos ingredientes da composição, em particular, o acelerador (TBBS) e o enxofre. Na composição NR1 que contém apenas o ácido esteárico, o qual é sólido em temperatura ambiente, tal fato não foi observado. Assim, é possível que a introdução dos ingredientes na borracha natural já solubilizados em óleo de linhaça e/ou amendoim tenha não apenas auxiliado na dispersão dos mesmos pela matriz, mas também tornado as reações iniciais mais rápidas - (a) o acelerador e/ou espécies derivadas reagiram com o enxofre; (b) o óxido de zinco reagiu com o ácido graxo e tornou-se solúvel na matriz de borracha na forma de $\mathrm{Zn}^{2+}$; e, (c) um complexo foi formado entre as espécies (a) e (b) $)^{[7]}$.

Tal hipótese pode ser corroborada quando a Tabela 3 é novamente interpretada. As composições NR2, NR3 e NR6, nas quais o ácido esteárico não está presente, apresentam sempre menores valores de $t_{s 1}$ e $t_{90}$. Consequentemente, as composições devem exibir taxas de reação maiores, fato que se verifica na Figura 1 para os dados experimentais obtidos em $160{ }^{\circ} \mathrm{C}$. O efeito global de temperaturas maiores sobre o processo de vulcanização atenua as diferenças entre as constantes de taxa das diferentes composições, embora o valor de $k$ para a composição NR2, apenas com óleo de linhaça, continue sendo sempre o maior.

Na Figura 2 é apresentado o gráfico e a superfície de resposta para o efeito dos óleos vegetais na variação da energia global de ativação do processo de cura. A energia de ativação $\left(\mathrm{E}_{\mathrm{a}}\right)$ é a energia cinética combinada que as partículas que colidem devem ter para a reação ocorrer. Se a energia cinética combinada das moléculas que colidem exceder $\mathrm{E}_{\mathrm{a}}$, e se as mesmas são orientadas convenientemente, elas são capazes de ultrapassar a barreira de energia de ativação e formar moléculas de produtos $^{[12]}$

Através da Figura 2 percebe-se que as composições NR2, NR3 e, particularmente, NR6 exibem os menores valores de $\mathrm{E}_{\mathrm{a}}$. A composição NR6 apresenta um valor de $\mathrm{E}_{\mathrm{a}}$ da ordem de $47 \mathrm{~kJ} / \mathrm{mol}$, o qual é quase duas vezes inferior ao valor de $\mathrm{E}_{\mathrm{a}}$ da composição padrão com ácido esteárico (NR1). Além disso, pela superfície de resposta ilustrada na Figura 2, a qual é obtida por regressão numérica dos valores experimentais conforme descrito por da Costa et al. ${ }^{[16]}$, valores progressivamente reduzidos de $\mathrm{E}_{\mathrm{a}}$ são encontrados conforme as composições utilizam teores maiores dos óleos vegetais em substituição ao ácido esteárico.

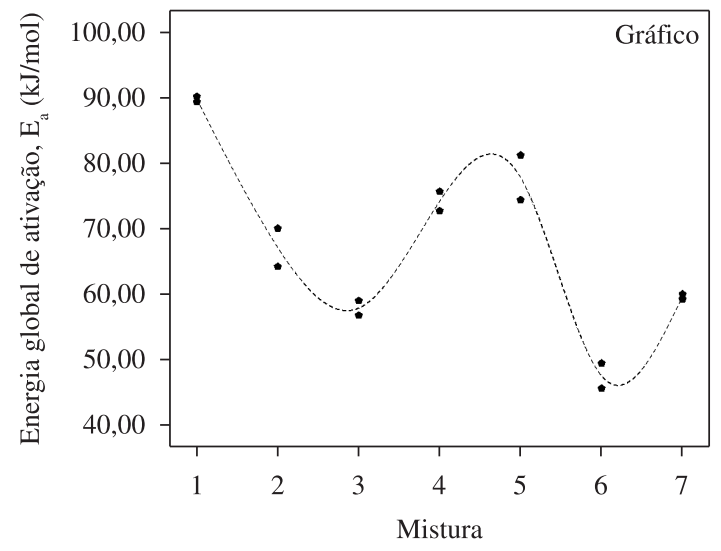

(a)

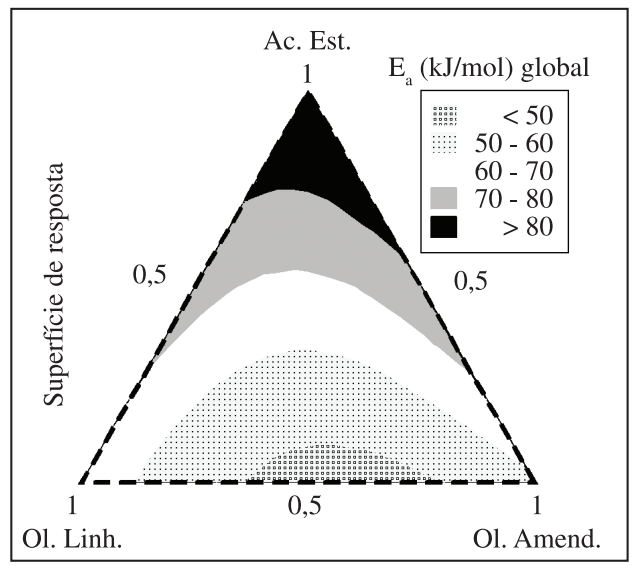

(b)

Figura 2. Efeito dos óleos vegetais na variação da energia global de ativação. (a) Gráfico com linha de tendência; (b) Superfície de resposta para a mistura dos ativadores 
Os resultados experimentais para $\mathrm{E}_{\mathrm{a}}$ seguem a lógica esperada, ou seja, se as composições NR2, NR3 e NR6 exibem os maiores valores de constante de taxa é porque, em tais composições, o processo global de vulcanização ocorre de maneira energeticamente favorável, em outras palavras, com uma energia de ativação pequena. Todavia, uma vulcanização mais rápida e com baixa $\mathrm{E}_{\mathrm{a}}$ não se traduz em uma rede de ligações cruzadas satisfatória, conforme discutido anteriormente na análise da Tabela 3.

Uma vulcanização adequada só passa a ocorrer quando um agente sulfurante ativo é formado. Tal espécie origina-se quando um complexo ativo do acelerador é formado através de uma interação preliminar entre o acelerador e o ativador (ácido graxo), na presença de zinco solúvel. Uma possível estrutura de tal espécie foi sugerida por Campbell e Wise ${ }^{[17,18]}$. Assim sendo, não apenas a quantidade formada, mas também a estabilidade do complexo precisa ser garantida, a fim de que um rendimento significativo no processo de formação de ligações cruzadas seja alcançado.

A análise da estrutura química dos principais ácidos graxos usados nesta investigação revela que ${ }^{[15]}$ :

- O ácido esteárico (ácido octadecanóico) é um ácido graxo saturado com 18 carbonos, de fórmula química $\mathrm{CH}_{3}\left(\mathrm{CH}_{2}\right)_{16} \mathrm{COOH}$

- Oóleo de amendoim possui como principal constituinte o ácido oléico (ácido cis-9-octadecenóico), o qual é um ácido graxo insaturado com 18 carbonos na sua estrutura e uma dupla ligação entre os carbonos 9 e 10. Há entre $35-72 \%$, de acordo com a Tabela 1 , em ácido oléico presente; $\mathrm{e}$

O óleo de linhaça, por sua vez, tem como principal componente o ácido linolênico (ácido cis, cis, cis-9,12,15-octadecatrienóico), o qual é um ácido graxo insaturado de 18 carbonos e três duplas ligações, com configuração cis, nos carbonos 9, 12 e 15. Há entre $52-54 \%$, de acordo com a Tabela 1, em ácido linolênico presente.

Três pontos, portanto, chamam a atenção e ajudam a explicar o menor desempenho das composições de NR contendo os óleos vegetais:

- Os isômeros cis e trans em alcenos não têm a mesma estabilidade. A tensão provocada pelos dois grupos alquila volumosos do mesmo lado de uma ligação dupla torna os isômeros cis menos estáveis do que os isômeros trans $^{[19]}$;

Uma reação característica dos compostos com uma ligação dupla carbono-carbono é uma adição. Duas características das ligações duplas ajudam a entender por que essas reações de adição ocorrem: (a) uma reação de adição resulta na conversão de uma ligação $\pi$ e uma ligação $\sigma$ em duas ligações $\sigma$. O resultado dessa mudança é geralmente favorável em termos de energia e as reações de adição são normalmente exotérmicas; (b) os elétrons da ligação $\pi$ estão expostos. Assim, a ligação $\pi$ é particularmente suscetível aos reagentes que procuram elétrons (reagentes eletrofílicos) ${ }^{[19]}$; e

- A dupla ligação presente na cadeia dos ácidos graxos pode ser oxidada, resultando em produtos cuja natureza depende do agente oxidante empregado e das condições de reação. Assim, uma oxidação enérgica produz a ruptura da cadeia, conduzindo à formação de ácidos dicarboxílicos e carboxílico. Nos triacilgliceróis com múltiplas insaturações, a auto-oxidação ocorre numa forma mais rápida; o mecanismo e o resultado dependem do número de duplas ligações existentes na cadeia do ácido graxo e do fato de serem conjugadas ou não conjugadas ${ }^{[20]}$.

Logo, a vulcanização é permitida em composições de NR onde o ácido estárico é substituído total ou parcialmente pelos óleos de linhaça e/ou amendoim. Porém, a presença de ácidos graxos insaturados em maior proporção nesses óleos compromete a estabilidade do complexo de zinco. Consequentemente, o processo de cura ocorre, mas atinge um rendimento final menor em densidade de ligações cruzadas (o valor de torque máximo, $\mathrm{M}_{\mathrm{h}}$, permite uma estimativa indireta) quando comparado ao processo da composição usual representado por NR1.

\section{Conclusões}

A presente investigação avaliou o efeito de óleos vegetais (linhaça e amendoim) sobre a vulcanização da borracha natural (NR) usando-se um sistema convencional de cura. Os resultados experimentais permitem concluir que:

- A vulcanização é permitida em todas as composições de NR , independente da presença do ácido esteárico;

- Os vulcanizados contendo apenas os óleos vegetais (amendoim e/ou linhaça) exibem os menores valores de $_{\mathrm{s} 1}$ e $\mathrm{t}_{90}$;

- Apenas nas composições em que o ácido esteárico está presente na mesma proporção que os óleos sozinhos ou combinados, NR4 (50\%/50\% ácido esteárico/óleo de linhaça), NR5 (50\%-50\% ácido esteárico/óleo de amendoim) e NR7 (33,3\%/33,3\%/33,3\% ácido esteárico/óleo de linhaça/óleo de amendoim), densidades de redes de ligações cruzadas próximas à da composição convencional (NR1) são obtidas, segundo análise dos valores de $\mathrm{M}_{\mathrm{h}}$; e

- A presença em grande proporção de ácidos graxos insaturados na composição química dos óleos parece ser a resposta para o entendimento dos resultados experimentais.

\section{Agradecimentos}

Os autores agradecem aos órgãos de fomento (CAPES, CNPq e FAPERJ) pelo suporte finaceiro e ao Instituto de Macromoléculas Professora Eloisa Mano (IMA/UFRJ) pelo apoio no desenvolvimento experimental desta investigação.

\section{Referências Bibliográficas}

1. Stephens, H. L. - "The compounding and vulcanization of rubber", in: Rubber Technology, cap.2, Morton, M., Kluwer Academic Publishers, Boston (1999).

2. Coran, A. Y. - "Vulcanization", in: The Science and Technology of Rubber, cap.7, Mark, J. E.; Erman, B.; Eirich, F. R., Eds., Academic Press, New York (2005).

3. Meier, M. A. R.; Metzger, J. O.; Schubert, U. S. - Chem. Soc. Rev., 36, p.788 (2007).

4. Metzger, J. O. - Eur. J. Lipid Sci. Technol., 111, p.865 (2009). 
5. Espinosa, L. M. \& Meier, M. A. R. - Eur. Polym. J., 47, p.837 (2011).

6. Ismail, H.; Salmiah, I. \& Tsukahara, Y. - Polym. Int., 44, p.523 (1997).

7. Ismail, H.; Anuar, H. \& Tsukahara, Y. - Polym. Int., 48, p.607 (1999).

8. Costa, H. M.; Ramos, V. D.; Abrantes, T. A. S.; Castro, D. F.; Visconte, L. L. Y.; Nunes, R. C. R. \& Furtado, C. R. G. - Polímeros, 14, p.46 (2004). http://dx.doi.org/10.1590/ S0104-14282004000100013

9. Aboissa óleos vegetais. Disponível em: <http://www. aboissa.com.br/produtos>.

10. Oliveira, I. T. D.; Pacheco, E. B. A. V.; Visconte, L. L. Y; Oliveira, M. R. L. \& Rubinger, M. M. M. - Polímeros, 20, p.366 (2010). http://dx.doi.org/10.1590/S010414282010005000059

11. Mykhopadhyay, R.; De, S. K. \& Chakraborty, S. N. - Polym., 18, p.1243 (1977).

12. Brady, J. E.; Russel, J. W. \& Holum, J. R. - "Cinética: o estudo das taxas de reação", in: Química - A matéria e suas transformações, cap.13, vol.2, 3. ed., LTC Editora, São Paulo 2003.
13. Chough, S. H. \& Chang, D. H. - J. Appl. Polym. Sci., 61, p.449 (1996).

14. Zhao, F.; Shi, X. \& Zhang, P. - J. Macromolecular Sci. Part B: Physics, 48, p.663 (2009).

15. Solomons, T. W. G. \& Fryhle, C. B. - "Lipídios", em: Química Orgânica, cap.23, vol.2, 7. ed., LTC Editora, São Paulo 2002

16. Da Costa, H. M.; Ramos, V. D.; Da Silva, W. S. \& Sirqueira, A. S. - Polym. Test., 29, p.572 (2010).

17. Campbell, R. H. \& Wise, R. W. - Rubber Chem. Tecnhol., 37, p.635 (1964).

18. Campbell, R. H. \& Wise, R. W. - Rubber Chem. Tecnhol., 37, p.650 (1964).

19. Solomons, T. W. G. \& Fryhle, C. B. - "Alcenos e Alcinos II: Reações de Adição”, in: Química Orgânica, cap.8, vol.1, 8. ed., LTC Editora, São Paulo 2005.

20. Fazenda, J. M. R. - "Óleos glicéridos, resinas alquídicas e poliésteres”, em: Tintas \& Vernizes, Ciência e Tecnologia, cap.3, 3. ed., Editora Edgard Blücher, São Paulo (2005).

Enviado: 01/11/11

Reenviado: 01/03/12

Aceito: 16/05/12 